\title{
Risk factors for development of transient tachypnea of newborns
}

\author{
Ghaith W. Hamdoon \\ Department of Pediatrics, College of Medicine, University of Mosul, Mosul, Iraq \\ Correspondence: Ghaith W. Hamdoon. drsabaweemosul@yahoo.com. \\ (Ann Coll Med Mosul 2018; 40 (1): 15-19). \\ Received: $2^{\text {nd }}$ Oct. 2013; Accepted: $19^{\text {th }}$ Mar. 2014.
}

\begin{abstract}
Background: Transient tachypnea of the newborn (TTN) is a frequently encountered form of neonatal respiratory distress. The underlying mechanism involves residual lung fluid that is delayed in clearance. TTN primarily occurs soon after birth and can last from 24 to 72 hours. Risk factors for TTN include elective cesarean section, male sex, late prematurity, low birth weight, macrosomia, polycythemia, maternal asthma and maternal diabetes. Treatment is often supportive with observation and potential oxygen supplementation.

Objective: To identify the risk factors associated with development of transient tachypnea of newborns who were delivered either normally or through cesarean section, at 36 weeks or beyound and to compare the results with those of others.

Patients and methods: This is a case -control study of 200 newborns suffering from respiratory distress during a period from the $1^{\text {st }}$ of September 2011 to the $1^{\text {st }}$ of September 2013 in the neonatal intensive care unit at AL-Kansaa Teaching hospital in Mosul. The perinatal history of newborns was analyzed. TTN was diagnosed on clinical basis and by exclusion of other diseases affecting the respiratory system including sepsis. The study included 200 healthy newborns as control.

Results: Multivariate analysis identified that the development of TTN was significantly associated with elective cesarean section $56 \%$ ( $p$-value $=0.001)$, male sex $66.5 \%$ ( $p$ - value $=0.001)$, late prematurity $21 \%$ ( $p$ value $=0.009)$, maternal diabetes $8 \%(P$-value $=0.014)$, maternal asthma $10.5 \%$ ( $p$-value $=0.01)$, birth asphyxia (low APGAR score) $9.5 \%$ ( $p$-value=0.005), low birth weight 16.5\% ( $p$-value=0.003), prolonged labor or using (forceps or vacuum) $22 \%$ ( $p$-value $=0.037$ ) and in vitro fertilization $2.5 \%$ ( $p$-value $=0.024$ ).

Conclusion: Transient tachypnea of newborns is strongly related to elective cesarean section, male sex, late prematurity, maternal diabetes, maternal asthma, birth asphyxia, low birth weight (1500-2500g), prolonged labor or using forceps or vacuum and in vitro fertilization.
\end{abstract}

Keywords: Transient tachypnea of newborn, elective cesarean section, low gestational weight, in vitro fertilization.

$$
\text { عوامل الخطورة لنشوع حالات تسارع التففس المؤقت للأطفال الحديثي الولادة }
$$

الخلفية: تعتبر حالات تسارع التنفس المؤقت للأطفال الحديثي الو لادة من الحالات الثائعة كجز ه من حالات عسر التنفس للأطفال

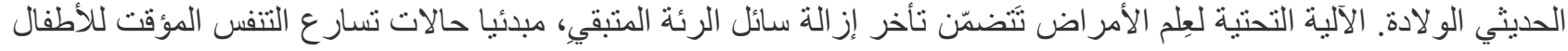

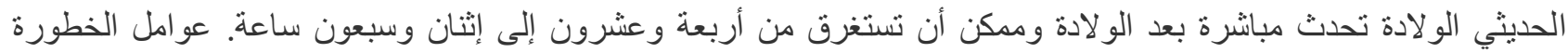

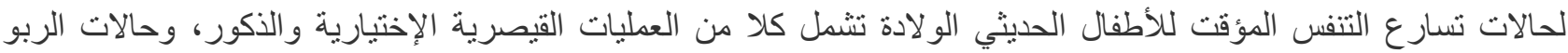

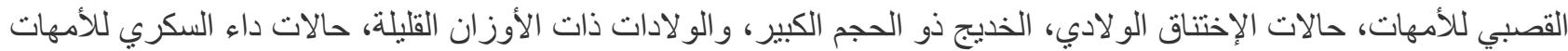

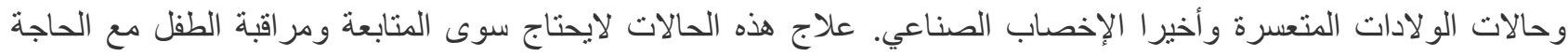
لإستعمال الأوكسيجين في بعض الألحات والحيان. 
الهدف: إن هدف هذه الدراسة هو تشخيص عوامل الخطورة لحالة تسارع التنفس المؤقتة لدى الأطفال المولودين حديثا سواء عن

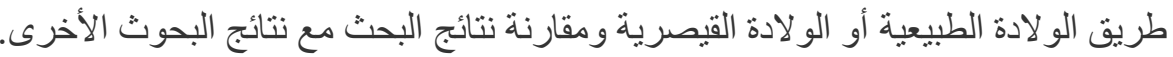

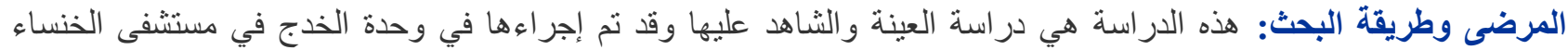

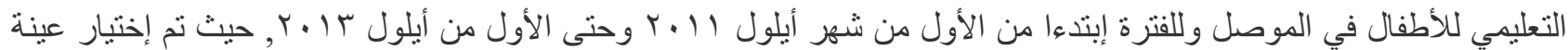

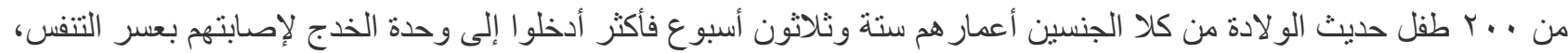

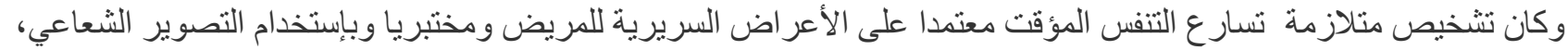

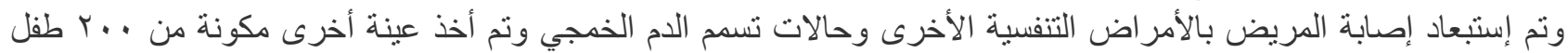

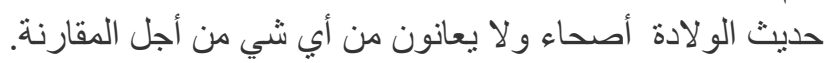

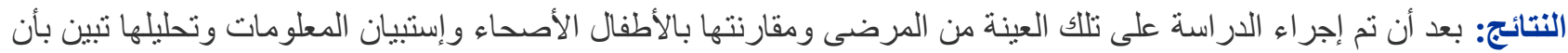

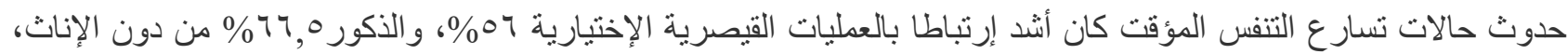

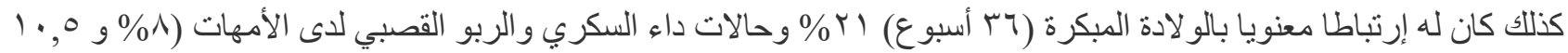

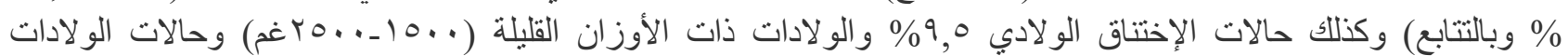

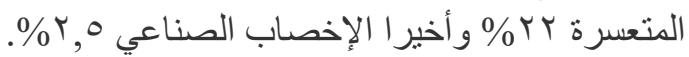

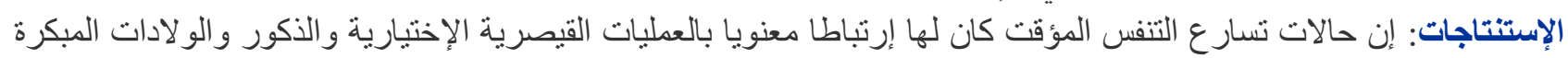

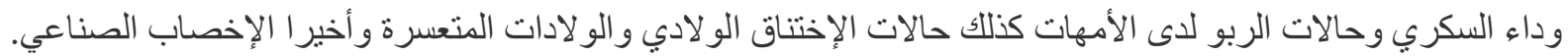

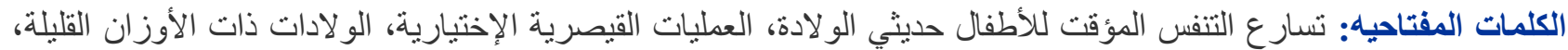
الإخصاب الصناعي.

\section{INTRODUCTION}

T ransient tachypnea of the newborn (TTN), first described by Avery in 1966, represents the most common cause of respiratory distress, and occurs in approximately $6 / 1000$ births. ${ }^{1,2}$

The incidence of neonatal respiratory distress in the newborn is approximately $7 \% .{ }^{1}$ In utero, fluid is produced by the neonatal lung. Some of this fluid is swallowed by the neonate and excreted by the kidneys resulting in amniotic fluid. The fetal larynx periodically opens and closes, so most of the fluid is swallowed but some fluid enters the lungs to keep them expanded. ${ }^{3}$

Lung fluid production drops as epinephrine levels increase, which also accelerates fluid transport via sodium channels. Recent studies have demonstrated that certain genetic abnormalities in catecholamine receptors can predispose a newborn to TTN. ${ }^{4}$

Malignant TTN has been reported in infants born by elective cesarean section who initially present with signs and symptoms of TTN that may last more than 72 hours. These infants demonstrate refractory hypoxia due to pulmonary hypertension and may require extracorporeal membrane oxygenation (ECMO). ${ }^{5}$
Transient tachypnea of the newborn represents the most frequent cause of neonatal respiratory distress among all newborns, constituting over $40 \%$ of cases. ${ }^{6}$

Newborns with TTN usually present with tachypnea intercostal or subcostal retractions, grunting, nasal flaring and poor feeding. Cyanosis is not common but could be present in severe cases. Symptoms can last from few hours to over 2 or 3 days. Although hypoxemia is not typical, it can be present. $^{7}$

Chest x-ray (CXR) can show hyperaeration, parenchymal infiltrates, and intralobar fluid accumulation. CXR findings, however, are often shared by other causes of respiratory distress and rarely fit classical description. TTN diagnosis is usually based on the clinical assessment. ${ }^{7}$ Copetti and Cattarossi demonstrated that differences in ultrasonographic findings between the upper and lower lung fields could potentially be diagnostic of TTN and can differentiate it from other causes of respiratory distress. Although tested in a small study using a high-resolution linear probe, the authors achieved a sensitivity and specificity rate of $100 \%$. These findings suggest the need for larger, blinded, prospective studies. ${ }^{7}$ 
Risk factors for the development of $\mathrm{TTN}^{7-9}$ include: elective cesarean section delivery without preceding labor (especially with gestational age < 38 weeks),maternal diabetes, maternal asthma, male sex ,multiple gestations, macrosomia (birth weight $>4 \mathrm{Kg}$ ) and precipitous delivery. Less common risk factors for TTN ${ }^{10,11}$ include: delayed clamping of umbilical cord (optimal time 45 seconds) which leads to increased placental transfusion and this causes left ventricular dysfunction, fluid overload of the mother, especially with oxytocin infusion, negative amniotic fluid phosphatidylglycerol, birth asphyxia, excessive maternal sedation and analgesia, exposure to Bmimetic agents, prolonged labor and polycythemia.

\section{Aims of the study}

1. To identify the risk factors associated with development of transient tachypnea of newborns.

2. To compare the results with others.

\section{PATIENTS AND METHODS}

This is a case-control study, it was conducted over two years period, from the $1^{\text {st }}$ of Sep. 2011 to the $1^{\text {st }}$ of Sep. 2013 in the neonatal intensive care unit at AL-Kansaa Teaching hospital in Mosul.

The perinatal history of two hundred newborns were reviewed regarding risk factors of TTN. They were delivered either by cesarean section or normally at $36 \geq$ weeks of gestation, all of them were suffering from respiratory distress that lasted $>6$ hours after delivery. Cases with suspicion of TTN were validated through the absence of other morbidities affecting respiration, particularly perinatal infection, persistent pulmonary hypertension and meconium aspiration syndrome. Complete perinatal and post natal history was taken to rule out other causes of respiratory distress. They were investigated by complete blood count, sepsis screen and chest $x$ ray. All sepsis screen results including (blood culture, c-reactive protein and complete blood count) were negative.

The diagnosis of TTN was based on exclusion and observation of clinical features based on clinical features of tachypnea, chest retractions, expiratory grunting and occasionally cyanosis that is relieved by minimal oxygen supplementation $(<40 \%)$. The chest examination revealed generally clear vesicular breath sound without rales or rhonchi and the chest radiograph showed prominent pulmonary vascular markings, fluid in the intralobar fissures, overaeration, flat diaphragms and rarely small pleural effusions.

The study also included two hundred healthy newborns as a control group, who were delivered either by cesarean section or normally. The perinatal and post natal history of these newborn were also reviewed for the presence of risk factors of TTN.

The studied risk factors for development of TTN were: elective cesarean section, male sex, gestational age $36 \geq$ weeks, maternal diabetes, maternal asthma, birth asphyxia (low APGAR score), prolonged labor or by using forceps or vacuum, history of in vitro fertilization, macrosomia, fluid overload of the mothers specially with oxytocin infusion, breech delivery, exposure to Bmimetic agent, precipitous delivery and multiple gestations.

Statistics were calculated by mean of chi-square test for categorical variables. Odd ratios and 95\% confidence intervals (Cls) were also calculated. Statistical analysis was performed and P-value of $<0.05$ was considered as a significant.

\section{RESULTS}

Table 1 showed that the risk factors; male sex, late prematurity, maternal diabetes, maternal asthma, birth asphyxia (low APGAR score $<7$ at 1 minute), low birth weight (1500-2500 g), prolonged labor or by using forceps or vacuum and in vitro fertilization, were significant causes of TTN (Pvalues were $0.001,0.009,0.014,0.01,0.005$, $0.003, \quad 0.037, \quad 0.024$ respectively). While macrosomia, precipitated delivery, multiple gestations, exposure to B- mimetic drugs, maternal $\mathrm{PET}$, maternal thyrotoxicosis, birth weight and fluid overload with oxytocin infusion failed to reach a significant level.

Table 2 showed the mode of delivery among the 2 groups. The number of patients who developed TTN was higher in those who were delivered by Cesarean section than normally with significant association $(P=0.001)$. Among those patients who were delivered by cesarean section, a higher number of patients with TTN were seen in those delivered by elective cesarean section compared to emergency cesarean section. 
Table 1. Distribution of risk factors among patients with TTN and control group.

\begin{tabular}{|c|c|c|c|c|c|c|c|}
\hline \multirow[t]{2}{*}{ Risk factors } & \multicolumn{2}{|c|}{$\begin{array}{c}\text { TTN } \\
(n=200)\end{array}$} & \multicolumn{2}{|c|}{$\begin{array}{l}\text { Control } \\
(n=200)\end{array}$} & \multirow[t]{2}{*}{ OR } & \multirow[t]{2}{*}{$95 \% \mathrm{Cl}$} & \multirow[t]{2}{*}{$\mathrm{p}$-value } \\
\hline & No. & $\%$ & No. & $\%$ & & & \\
\hline & 133 & 66.5 & 96 & 48 & \multirow{2}{*}{2.578} & \multirow{2}{*}{$1.720-3.865$} & \multirow{2}{*}{$0.001(\mathrm{~s})$} \\
\hline Female & 67 & 33.5 & 104 & 52 & & & \\
\hline \multirow{2}{*}{$\begin{array}{ll}\text { Gestational age } & <36 \text { wks } \\
& \geq 36 \text { wks }\end{array}$} & 42 & 21 & 22 & 11 & 0.986 & $0.772-1.226$ & \multirow{2}{*}{0.009 (s) } \\
\hline & 158 & 79 & 178 & 94 & 0.465 & $0.267-0.809$ & \\
\hline Maternal diabetic & 16 & 8 & 5 & 2.5 & 3.391 & $1.262-9.089$ & $0.014(\mathrm{~s})$ \\
\hline Maternal asthma & 21 & 10.5 & 8 & 9 & 2.816 & $1.240-6.384$ & $0.01(\mathrm{~s})$ \\
\hline Macrosomia >4kg & 8 & 4 & 7 & 3.5 & 1.149 & $9.424-3.110$ & 1.000 \\
\hline Precipitous delivery & 4 & 2 & 2 & 1 & 2.02 & $0.427-9.533$ & 0.411 \\
\hline Multiple gestation & 2 & 0 & 17 & 8.5 & 0.109 & $0.028-0.430$ & 0.001 \\
\hline $\begin{array}{l}\text { Birth asphyxia. (APGAR score }<7 \text { at } 1 \\
\text { minute) }\end{array}$ & 19 & 9.5 & 5 & 2.5 & 4.094 & $1.549-10.790$ & 0.005 (s) \\
\hline Birth wt. $\quad$ Normal birth wt & $\begin{array}{c}33 \\
167\end{array}$ & $\begin{array}{l}16.5 \\
83.5\end{array}$ & $\begin{array}{c}14 \\
186\end{array}$ & $\begin{array}{c}7 \\
93\end{array}$ & 2.625 & $1.369-5.028$ & 0.003 \\
\hline $\begin{array}{l}\text { Prolonged labor or by using (forceps or } \\
\text { vacuum) }\end{array}$ & 44 & 22 & 28 & 16.5 & 1.682 & $1.001-2.828$ & 0.037 \\
\hline Breech delivery & 8 & 4 & 2 & 2 & 4.125 & $0.976-17.358$ & 0.055 \\
\hline Exposure to B-mimetic agent & 2 & 1 & 0 & 0 & Inf & o.521-inf & 0.499 \\
\hline Maternal PET & 1 & 0.5 & 0 & 0 & Inf & 0.260-inf & 1.00 \\
\hline Maternal thyrotoxicosis & 1 & 0.5 & 0 & 0 & $\operatorname{lnf}$ & 0.260 -inf & 1.00 \\
\hline Fluid overload+oxytocin infusion & 2 & 0.2 & 1 & 0 & Inf & 1.322-inf & 0.124 \\
\hline In vitro fertilization & 5 & 2.5 & 0 & 0 & Inf & 1.322-inf & $0.024(s)$ \\
\hline
\end{tabular}

Table 2. Mode of delivery among the patients with TTN and control group.

\begin{tabular}{|c|c|c|c|c|c|c|c|c|}
\hline \multirow{2}{*}{\multicolumn{2}{|c|}{ Mode of delivery }} & \multicolumn{2}{|c|}{$\begin{array}{c}\text { Patients with } \\
\text { TTN } \\
\text { N=200 }\end{array}$} & \multicolumn{2}{|c|}{$\begin{array}{l}\text { Control group } \\
\qquad N=200\end{array}$} & \multirow[t]{2}{*}{ OR } & \multirow[t]{2}{*}{$95 \% \mathrm{Cl}$} & \multirow[t]{2}{*}{$P$ value } \\
\hline & & No. & $\%$ & No. & $\%$ & & & \\
\hline \multirow{2}{*}{ Cesarean section } & Elective & 112 & 56 & 58 & 29 & \multirow{4}{*}{6.817} & \multirow{4}{*}{$4.399-10.563$} & \multirow{4}{*}{$0.001(\mathrm{~s})$} \\
\hline & emergency & 37 & 18.5 & 29 & 14.5 & & & \\
\hline \multicolumn{2}{|c|}{ Normal vaginal delivery } & 51 & 25.5 & 113 & 56.5 & & & \\
\hline \multicolumn{2}{|l|}{ Total } & 200 & 100 & 200 & 100 & & & \\
\hline
\end{tabular}

\section{DISCUSSION}

The present study showed that TTN was more common in males $(66.5 \%)$ than females $(38.5 \%)$, which was comparable with Kasap B et al (2008), ${ }^{6}$ Asenjo M (2007), ${ }^{12}$ and AL-jurjari Z (2012), ${ }^{13}$ and Erol Tutdibi et al (2009). ${ }^{14}$

The TTN was more common in those newborns with gestational age of $\geq 36$ weeks (late premature, $21 \%$ ), which was comparable with Kasap B et al $(2008)^{6}$ and Erol Tutdibi et al (2009) ${ }^{14}$ who found a significant association between TTN and late prematurity.

There was a significant association between low birth weight (1500-2500) and TTN ( $P=0.003)$, as also found by Liem JJ (2007), ${ }^{15}$ and Tutdibi Erol (2010). ${ }^{14}$ Both found a significant relationship between TTN and low birth weight.
No significant association was found between the most frequently encountered birth weight (2500-3000 grams) and TTN, and this may be due to small sample in this study.

A significant association was found between elective cesarean section delivery and TTN. This was similar to those found by Levine EM. (2001), ${ }^{9}$ AL-jurjari Z (2012), ${ }^{13}$ Liem JJ (2007), ${ }^{15}$ and Erol Tutdibi et al (2009), ${ }^{14}$ who found an increase of TTN by $2-3$ folds in the neonates delivered by elective cesarean section than those delivered normally $(P=0.001)$. Infants delivered through elective cesarean section often are deprived of the labor-related physiological stress response pattern at birth and consequently experience failure of postnatal respiratory transition. 
A significant association between TTN and diabetic mothers was found, this was similar to that found by Dani C (1999), ${ }^{8}$ AL-jurjari Z (2012) ${ }^{13}$ and Nazarzaki (2008). ${ }^{16}$ Also a significant association was found between TTN and asthmatic mothers, which is the same in AL-jurjari Z (2012), ${ }^{13}$ Liem, JJ (2007), ${ }^{15}$ and Subramanian KNS et al (2006), ${ }^{17}$ studies.

Birth asphyxia (low APGAR score $<7$ at 1 minute) was also found to be significantly associated with TTN, which is similar to Michael S (1991) ${ }^{18}$ results.

Prolonged labor or by using forceps or vacuum also had a significant correlation with TTN, in which it may cause dysfunctional catecholamine regulation, mild pulmonary capillary leak and myocardial dysfunction, which was similar to Erol Tutdibi et al (2009) ${ }^{14}$ findings.

A significant correlation was found between TTN and in vitro fertilization, which is comparable to Takayata et al (2008) ${ }^{19}$ findings.

\section{CONCLUSION}

Transient tachypnea of newborns is significantly correlated with elective cesarean section, late prematurity, male sex, maternal asthma, maternal diabetes, birth asphyxia prolonged labor and in vitro fertilization.

\section{RECOMMENDATIONS}

1. Good antenatal care is crucial in detecting early problems during pregnancy that may have relation to increase incidence of TTN.

2. Good obstetric care during delivery has an important role in prevention of perinatal asphyxia which by itself may lead to increase incidence of TTN.

\section{REFERENCES}

1. Kumar A and Bhat BV. Epidemiology of respiratory distress of newborns. Indian J. Pediatr 1966; 63(1): 9398.

2. Avery ME, Gatewood OB, Brumley G. Transient tachypnea of newborn possible delayed resorption of fluid at birth. Am. J. Dis. Child. 1966; 111(4): 380-385.

3. Blackburn ST: Maternal fetal and neonatal physiology: a clinical perspective ( $3^{\text {rd }}$ Edition). Elsevier Health Sciences, MO, USA; 2007: 338.

4. Aslan E, Tutdibi E, Martens S, et al. Transient tachypnea of the newborn (TTN): a role for polymorphisms in the b-adrenergic receptor (ADRB) encoding genes? Acta Paediatr. 2008; 97(10): 13461350.
5. Waldemar A. carlo. Respiratory tract disorders in NB Behram, Richerd, Robert $M$ et al Nelson Textbook of pediatrics. $19^{\text {th }}$ ed. Philadelphia, WB Saunders Co: 2011; 95.4:P579-99.

6. Kasap B, Duman N, Ozer E, et al Transient tachypnea of the newborn: predictive factor for prolonged tachypnea. Pediatr Int.2008; 50:81-84.

7. Copetti R, Cattarossi L. The 'double lung point. An ultrasound sign diagnostic of transient tachypnea of the newborn. Neonatol. 2007; 91: 203-209.

8. Dani C, Reali MF, Bertini G, et al. Risk factors for the development of respiratory distress syndrome and transient tachypnea in newborn infants. Eur Respir J. 1999; 14: 155-159.

9. Levine EM, Ghai V, Barton JJ, Strom CM. Mode of delivery and risk of respiratory diseases in newborns. Obstet Gynecol 2001; 97: 439-42.

10. Tutdibi E, Gries K, Bucheler N, et al. Impact of labor on outcome in transient tachypnea of the newborn. Pediatrics 2010; 125: 577- 583.

11. John P. Cloherty, Eric C Eichenwald, Anne R. Honsen. Manual of neonatal care. $17^{\text {th }}$ ed. Philadelphia, PA: Lippincott Williams \& Wilkin; 2012; 24G: PP403-405. 12. Asenjo M. Transient tachypnea of the newborn. $E$ medicine. 1 ; 2007:943-987.

13. ALjurjari Z. Risk factors for Transient tachypnea of newborn. Dissertation submitted to the Iraqi Board for medical specialization in partial fulfillment for the degree of fellowship of the Iraqi Board for medical specialization in pediatrics. 2013.

14. Tutdibi, Erol; Gries, Katharina; Bücheler, Monika; Misselwitz, Bjorn; Schlosser, Rolf L; Gortner, Ludwig. Impact of labor on outcomes in transient tachypnea of the newborn: population based study. Pediatrics 2010; 125: $577-583$.

15. Liem JJ, Huq SI, Ekuma, O, Becker AB, Kozyrskyi AL. Transient tachypnea of the newborn may be an early clinical manifestation of wheezing symptoms. J Pediatr 2007; 151:29.

16. Zeki N. Risk factors for Transient tachypnea of newborn. Dissertation submitted to the Iraqi Board for medical specialization in partial fulfillment for the degree of fellowship of the Iraqi Board for medical specialization in pediatrics. 2008.

17. Subramanian KNS, Bahri M, Kicklighter DS. Transient tachypnea of the new born. E medicine 2006; 54:1-11.

18. Michael S, Robert S, Clement P. Hoffman, Brian S, Kathleen M, Alan B Forsythe. Increase transient tachypnea of newborn in infants of asthmatic mothers Am J Dis Child. 1991; 145(2):156-158.

19. Takayata A, Igarashi $M$, Nakajima $M$, Miyaki $H$, Shima Y, Zusuki S. Risk factors for transient tachypnea of newborn in infant delivered vaginally at 37 weeks or later. J Nippon Med Sch 2008; 75: 269-273. 